\title{
Imagistic Technique and Fractal Analysis - Investigations Mechanisms of the Morphological and Temporal Variability of the Wheat Cultures
}

\author{
Ciprian RUJESCU, Cosmin POPESCU, Hamzeh RAWASHDEH, Florin SALA*
}

\begin{abstract}
The dynamic analysis of the vegetal carpet and of the vegetal cultures, presenting high interest for the management of natural balances and of agricultural systems efficiency. The fractal analysis has been used for the assessment of the morphological and temporal variability within the Triticum aestivum L. ssp. Vulgare species, in four cultivars of non-awned wheat (Avenue, Pitbull, GK Koros and Illico) and 6 awned cultivars (GK Rozi, PG 101, GK Bekes, GK 102, Antonius și Stefanus). The study has been performed in three different vegetation stages: Growth stage 3 - Stem elongation, code 33 BBCH; Growth stage 6 - Flowering, anthesis, code 69 BBCH,and Growth stage 9 - Senescence, code $99 \mathrm{BBCH}$. The fractal dimensions have been between $1.879 \pm 0.067$ and $1.963 \pm 0.046$. From the perspective of the variability induced by cultivars, two distinct clusters have resulted, $G_{N A}$ cluster including the non-awned cultivars $(C 1-C 4)$ and a second cluster, $G_{A}$ including the awned cultivars $(C 5-C 10)$ and subclusters depending on the similarity of cultivars. From the point of view of the temporal variability the obvious difference of Growth stage 9 ( 99 BBCH code), with the variation coefficient within the fractal dimenssion $C V 9=1.448 \pm 0.005(p<0.01)$. The fractal dimension obtained using the digital images can be useful for the dissociation of awned I non-awneed cultivars, but only the higher stages of wheat development. It is also useful for the delimitation of wheat development stages.
\end{abstract}

Keywords: box-counting; fractal dimension; growth stage; similarity; variability; wheat

\section{INTRODUCTION}

The usual identification of plants and of vegetal associations is a problem that has exceeded the boundaries of botany, being also in the sphere of other more comprehensive disciplines: ecology, plant physiology, genetics, geography, etc. Also some related areas such as bio-economy, precision farming, bio-resources and others, are interested in the possibility of effective real-time assessment of the state of natural or cultivated vegetation, the level of crop safety, agricultural or biomass production as well as quality or efficiency aspects[1-10].

A large number of real-world systems and subsystems present similar behaviors within variable observation and analysis scales. Most biological structures have the property of self-similarity on the basis of which they can be considered approximate fractals [11].

A major interest has been focused on the use of fractal analysis for the study of various types of textures, as a result of the high degree in which they may reflect certain realities in the surrounding world [1, 6, 12-14]. Thus, in some studies on certain structures, granite mineral rocks [15], nano-structural materials [16] and others; similar representations of textures have been obtained by the fractal analysis, the method facilitating a clear view of the target elements.

Fractal analysis is a powerful tool for the evaluation and characterization of plants, which has the power to extract information based on anatomic morphological features such as shape, size, contour-line, ribs (of various grades), pilosity, trichomes, pustules, anatomical formations, typical colorations / discolorations, marginal or apical endings, etc. [17-19], changes and transition of vegetation [20, 21]. Li et al. (2016) [22] used the fractal analysis technique to determine the changes that occur in soil properties.

According to the increased interest in promoting efficient methods of evaluation and characterization of vegetal carpet and agricultural crops, the aim of the study is to highlight morphological and temporal similarities and variabilities in 10 wheat cultivars (Triticum aestivum L. ssp. vulgare) based on the fractal dimenssions $(D)$.

\section{MATERIALS AND METHODS \\ 2.1 Biological Material}

The studied biological material has been Triticum aestivum L. ssp. Vulgare species, with four non-awned varieties (Avenue, Pitbull, GK Koros and Illico) and 6 awned varieties (GK Rozi, PG 101, GK Bekes, GK 102, Antonius and Stefanus). The study has been carried out during three different stages of vegetation taking into consideration the phisiological and morpho-anatomical aspects: Growth stage 3 (GS 3) - Stem elongation, code 33 BBCH; Growth stage 6 (GS 6) - Flowering, anthesis, code $69 \mathrm{BBCH}$ and Growth stage 9 (GS 9) - Senescence, code $99 \mathrm{BBCH}$.

\subsection{Capture of Digital Images}

Digital images were captured randomly, within each variety, during the three distinct stages of vegetation. The image capture was performed using a Nikon D300, $12 \mathrm{MP}$, DX format, $24 \mathrm{~mm}$ focal length lens, $1.5 \mathrm{~m}$ soil clearance. The images obtained (Fig. 1) (24 bits) were analyzed unitarily to extract fractal data.

\subsection{Fractal Analysis}

The Box-Counting method was used to determine the fractal dimension $(D)$ on the basis of which morphological and temporal similarity and variability were assessed in the 10 studied wheat cultivars.

A number of recent research studies have indicated box-counting method as being very realistic for determining fractal dimension [23-25]. The software ImageJ [26] and FracLac plugin [27] were used for the fractal analysis, the analysis being carried out on binarized images. Series of analyses have been performed on the binarized images in order to extract the fractal dimension $(D)$, using the formula $D=m[\ln (F) / \ln (\varepsilon)]$, where $\mathrm{m}$ is 
the slope to regression line, $F$ - number of new part, and $\varepsilon$ - scale applied to an object.

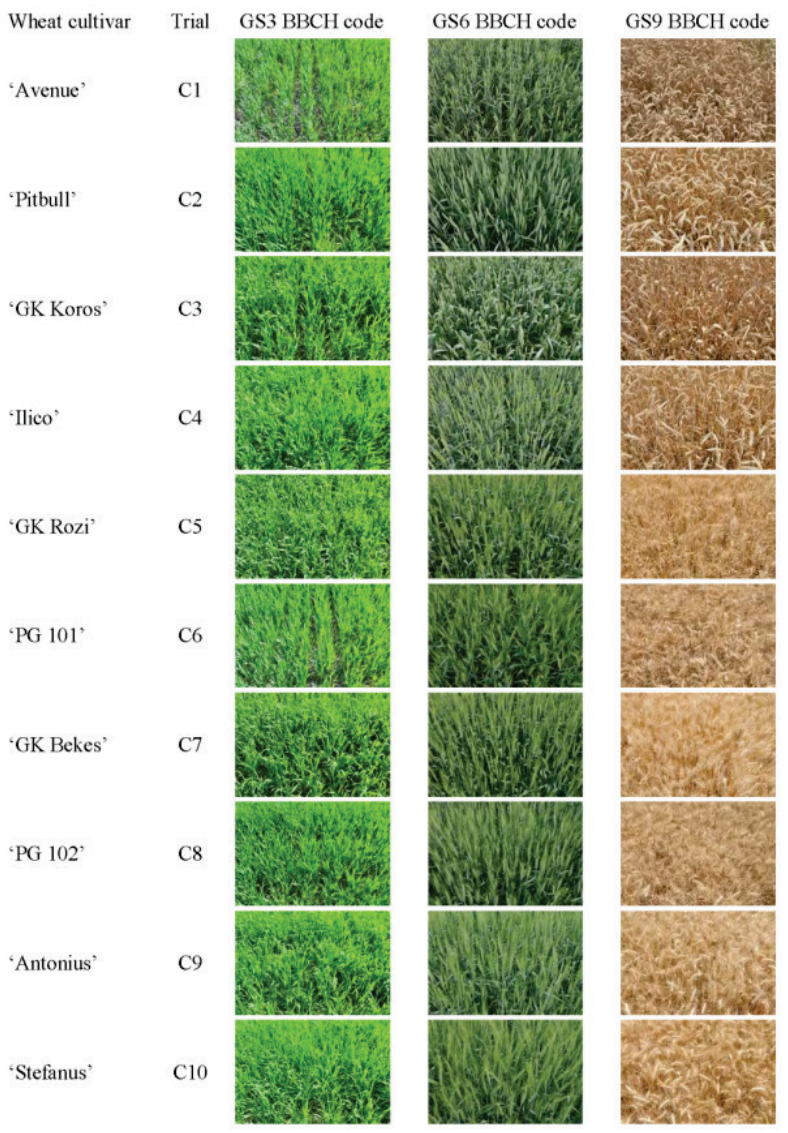

Figure 1 Images of wheat cultivars in different vegetation stage (GS 3 - Stem elongation, GS 6 - Flowering, anthesis, GS 9 - Senescence, BBCH code)

\subsection{The Statistic Analysis of the Results}

The statistic testing in view of assessing the differences between groups, have been performed using SPSS. The correlation coefficient, variation coefficient
$(\mathrm{CV})$, Principal Component Analysis (PCA) and Cluster analysis have been performed using the PAST software [28], being used for the fractal characterising of the studied wheat cultivars in view of assessing their morphological and temporal variation.

\section{RESULTS AND DISCUSSIONS}

In the case of non-awned cultivars (Avenue, Pitbull, GK Koros and Ilico) the fractal dimensions have been ranged between $1.879 \pm 0.067$ and $1.906 \pm 0.072$, and for the awned cultivars (GK Rozi, PG 101, GK Bekes, PG 102, Antonius and Stefanus) ranged between $1.937 \pm 0.036$ and $1.963 \pm 0.046$, and presented variations within each group of cultivars depending on the vegetation stages, Tab. 1. The correlation coefficient calculated for the determination of the fractal dimensions has lead to values of $R^{2} \in 0.995$ 0.999 .

Morphological variability was given by the features of wheat cultivars at the same stage of vegetation, and the temporal variability was given by the morpho-anatomic properties of the wheat cultivars during the dynamics of the vegetation stages and evidenced by the fractal dimensions (D).

Growth stage 3 (GS 3) Stem elongation (code 33 $\mathrm{BBCH})$, specific for vegetative growth phenophase, was characterized by a high degree of plant morpho-anatomic uniformity, the differences in the amount of biomass being relatively small. In this stage, the fractal analysis has revealed the high degree of uniformity of studied wheat varieties, the average fractal dimension having the value $D$ $=1.931$ for the non-awned cultivars and $D=1.929$ for the awned cultivars.

In generative phenophase, Growth stage 6 (GS 6), Flowering, anthesis (code 69 - BBCH), the studied wheat cultivars presented morpho-anatomical characteristics newly generated by the ears. The average value of the fractal dimension $(D)$ in the non-awned cultivars was $D=$ 1.915 , and in awned cultivars was $D=1.911$.

Table 1 Fractal dimensions $(D)$ in wheat crop, depending on cultivar and vegetation stage

\begin{tabular}{|c|c|c|c|c|c|}
\hline \multirow[b]{2}{*}{ Wheat cultivar } & \multirow[b]{2}{*}{ Trial } & \multicolumn{3}{|c|}{ Fractal Dimension $(D)$ in the growing stages analyzed } & \multirow[b]{2}{*}{ Awned } \\
\hline & & $\begin{array}{c}\text { Growth stage } 3 \text { Stem elongation, } \\
\text { code } 33 \mathrm{BBCH}\end{array}$ & $\begin{array}{c}\text { Growth stage } 6 \text { Flowering, anthesis, } \\
\text { code } 69 \mathrm{BBCH}\end{array}$ & $\begin{array}{l}\text { Growth stage } 9 \text { Senescence, } \\
\text { code } 99 \mathrm{BBCH}\end{array}$ & \\
\hline Avenue & $C 1$ & $1.949 \pm 0.056$ & $1.936 \pm 0.048$ & $1.906 \pm 0.072$ & No \\
\hline Pitbull & $C 2$ & $1.927 \pm 0.052$ & $1.908 \pm 0.056$ & $1.879 \pm 0.067$ & No \\
\hline GK Koros & $C 3$ & $1.919 \pm 0.054$ & $1.900 \pm 0.051$ & $1.899 \pm 0.070$ & No \\
\hline Ilico & $C 4$ & $1.929 \pm 0.050$ & $1.917 \pm 0.059$ & $1.894 \pm 0.065$ & No \\
\hline GK Rozi & $C 5$ & $1.941 \pm 0.059$ & $1.912 \pm 0.040$ & $1.951 \pm 0.044$ & Yes \\
\hline PG 101 & C6 & $1.942 \pm 0.059$ & $1.921 \pm 0.041$ & $1.957 \pm 0.048$ & Yes \\
\hline GK Bekes & $C 7$ & $1.915 \pm 0.046$ & $1.917 \pm 0.044$ & $1.937 \pm 0.036$ & Yes \\
\hline PG 102 & $C 8$ & $1.926 \pm 0.051$ & $1.914 \pm 0.043$ & $1.963 \pm 0.046$ & Yes \\
\hline Antonius & $C 9$ & $1.919 \pm 0.048$ & $1.895 \pm 0.039$ & $1.941 \pm 0.034$ & Yes \\
\hline Stefanus & $C 10$ & $1.928 \pm 0.054$ & $1.907 \pm 0.036$ & $1.937 \pm 0.043$ & Yes \\
\hline
\end{tabular}

At the physiological maturity, Growth stage 9 (GS 9), Senescence (code $99 \mathrm{BBCH}$ ), the average value of the fractal dimension of the non-awned cultivars was $D=$ 1,896 and for awed varieties $D=1,948$. The ears, due to the specific morpho-anatomic peculiarities of the two groups of cultivars (awned and non-awned) was the factor that had significantly differentiated the fractal properties of the studied wheat cultivars. Two intervals of values for fractal dimensions $(D)$ were estimated: a $D_{\mathrm{NA}}$ interval for non-awned cultivars, $D_{\mathrm{NA}} \in(1.879,1.906)$ and $D_{\mathrm{A}}$ interval for awned cultivars, $D_{\mathrm{A}} \in(1.937,1.963)$.

The coefficient of variation $(\mathrm{CV})$ of the fractal dimension $(D)$ values revealed the differentiated morphological and temporal variability of the two categories of cultivars in relation to the vegetation stages. The lowest variability was recorded in Growth stage 3 Stem elongation (code $33-\mathrm{BBCH}$ ), with the coefficient of variation in the fractal dimension $(D), C V 3=0.554 \pm 0.002$ $(p<0.01)$. In generative phenophase, Growth stage 6 Flowering, Anthesis (code 69 - BBCH), the coefficient of 
variation was $C V 6=0.603 \pm 0.002(p<0.01)$, and highlighting higher variability of wheat cultivars. The highest morphological and temporal variability of the two categories of cultivars was recorded at the physiological maturity, the coefficient of variation being $C V 9=1.448 \pm$ $0.005(p<0.01)$.

Monitoring the distribution of fractal dimension $D$ values for the "awned" and "awnless" cultivars, it was observed that in the GS 3 and GS 6 stages, they have similar values (Fig. 2). However, during the GS 9 development stage, the differences between $D$ values are more important: the values of the fractal dimension are higher in awned cultivars (with an average of 1.94 and a standard deviation of 0.01$)$, than in awnless cultivars (1.89 average, and standard deviation 0.01 ).

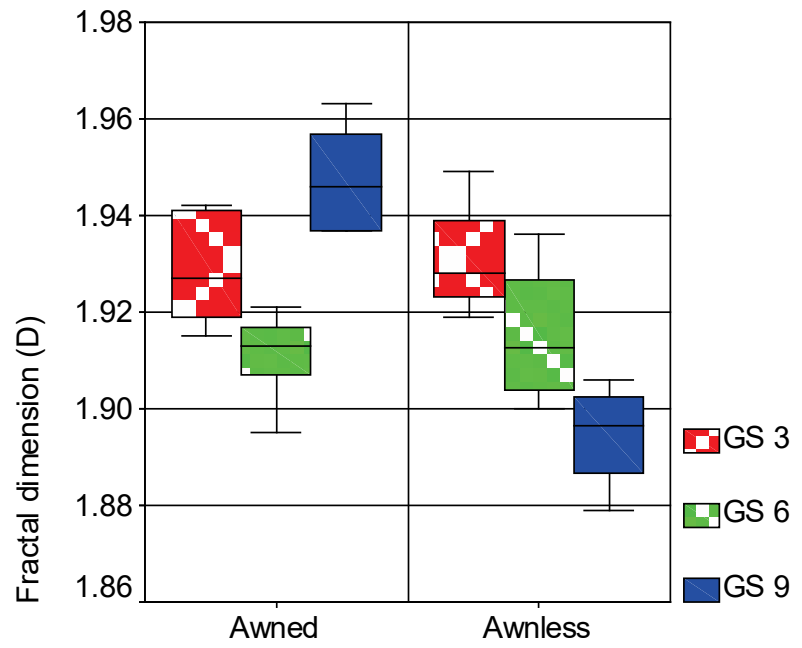

Figure 2 Boxplot diagram for fractal dimension $(D)$ of "awned" cultivars respectively "awnless" during the three followed stages of development

This has been statistically confirmed using $t$-test, independent samples. Thus, only at GS 9 stage, there were significant differences between the "awned" and "awnless" groups at the level $\alpha=5 \%$, namely $t=-13.005, p<0.001$. In GS 3 and GS 6 developmental stages there were no statistical differences between $D$ values, $p>0.05$. In fact, the same results were confirmed also in the use of a nonparametric test, Mann-Whitney. Thus, only at GS 9 stage, there were significant differences between the "awned" and "awnless" groups at the level $\alpha=5 \%$, namely $U<0.001, p$ $<0.001$. In GS 3 and GS 6 development stages there were no statistical differences between $D$ values, $p>0.05$. Moreover, differences were observed between the fractal dimensions determined between the three development stages of the wheat plants. Thus, using Oneway ANOVA, significant differences are confirmed, with $F=6.67$ and $p$ $=0.002$. Also, using the Kruskal-Wallis non-parametric test, values significantly different are recorded at the level $\alpha=5 \%$, having $x^{2}=16.517$ and $p<0.001$. Thus, the fractal dimension obtained from aerial images of wheat crops can provide support for the dissociation of the awned/awnless cultivars but only in the higher stages of wheat development. This indicator can also be used to separate the development stages of wheat.

A series of researches focused on the identification and characterization of plant species by leaves' fractal analysis, considered as organs with unique and specific features [18, 20, 29]. Du et al. (2008) [30] presented a database for various plants indicating classification methods. Araujo Mariath et al. (2010) [31] studied the leaf vascular system by fractal dimension of three species Relbunium $(R$. megapotamicum, $R$. hirtum and $R$. hypocarpium) indicating the utility of such a procedure.

In the case of this study, the particularities of the ear, i.e. the awns (C1-C4 non-awned cultivars, and $C 5-C 10$ awned cultivars) were the defining elements in the fractal dimensioning on the basis of which it was possible to evaluate the morphological and temporal similarity and variability of the 10 studied wheat cultivars.

The topological analysis of the wheat cultivars, based on the fractal dimensions, has facilitated the dendrogram drawing which reflects the degree of similarity and morphological and temporal variability of the studied wheat cultivars. Based on the Euclidean distances (twoway layout), a data arrangement emerged from the perspective of cultivars and vegetation stages.

From the perspective of cultivars-induced variability, two distinct clusters have resulted, a $G_{\mathrm{NA}}$ cluster comprising non-awned cultivars $(C 1-C 4)$, and the second $G_{\mathrm{A}}$ cluster comprising awned cultivars $(C 5-C 10)$, Fig. 3.
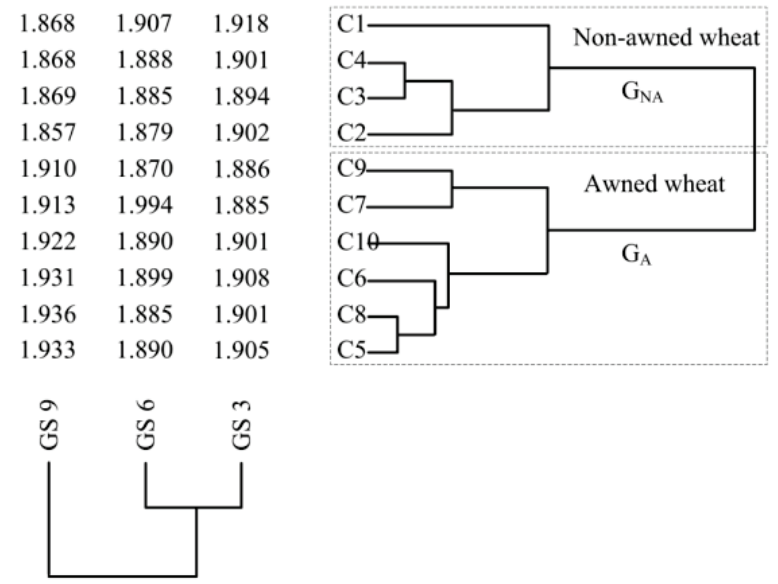

Figure 3 Dendrogram of cluster analysis in winter wheat cultivars based on fractal dimension $(D)$, two-way disposing; GS 3, GS 6, GS 9 - growth stage; GNA - non-awned wheat group; $G_{A}$ - awned wheat group

In the group of non-awned cultivars $\left(G_{\mathrm{NA}}\right)$, two subclasses have been outlined, a high degree of similarity being revealed in $C 3$ and $C 4$ cultivars. The group of awned cultivars $\left(G_{\mathrm{A}}\right)$ also included two sub-clusters, a high degree of similarity presenting cultivars $C 5$ and $C 8$. From the perspective of the vegetation stages-induced variability, two distinct clusters resulted, a cluster comprising the GS 3 and GS 6 stages that generated reduced variability, and the GS 9 stage in an independent position which had a major contribution to the differentiation of the results.

The cophenetic coefficient was 0.998 , indicating a high degree of safety in grouping and separating the biological material based on Euclidean distances resulting from fractal dimensions values $(D)$. In other studies, fractal analysis proved to be a powerful tool that had facilitated the extraction of essential information of the analyzed objects in the form of the fractal dimensions $(D)$ and which subsequently allowed a clear detection through cluster analysis (Euclidian distances) or PCA [32, 33].

The results of the PCA analysis were in compliance with the variants group based on Euclidean distances. The 
first two main components of PCA explained $83.576 \%$ of the variance and allowed the differentiation of the studied biological material (Fig. 4).

PCA analysis based on the obtained fractal dimensions $(D)$ facilitated the obvious grouping and separation of the studied cultivars into two distinct, awned/non-awned groups, with $P C 1$ variation of $57.318 \%$ and $26.258 \%$ respectively in $P C 2$.

Imaging techniques, using computer vision, have also been developed and used in other studies at Triticum, for the identification and classification of wheat grains, with a high accuracy rate of $88.33 \%$ [34] and 94\% [35].

Fractal analysis, as part of the imagistic technique, is therefore a tool that can be successfully used in the evaluation and characterization of the fractal geometry, in order to evaluate, classify and diagnose the variability of agricultural crops, plant carpet, or of dynamics of processes and phenomens in time and space.

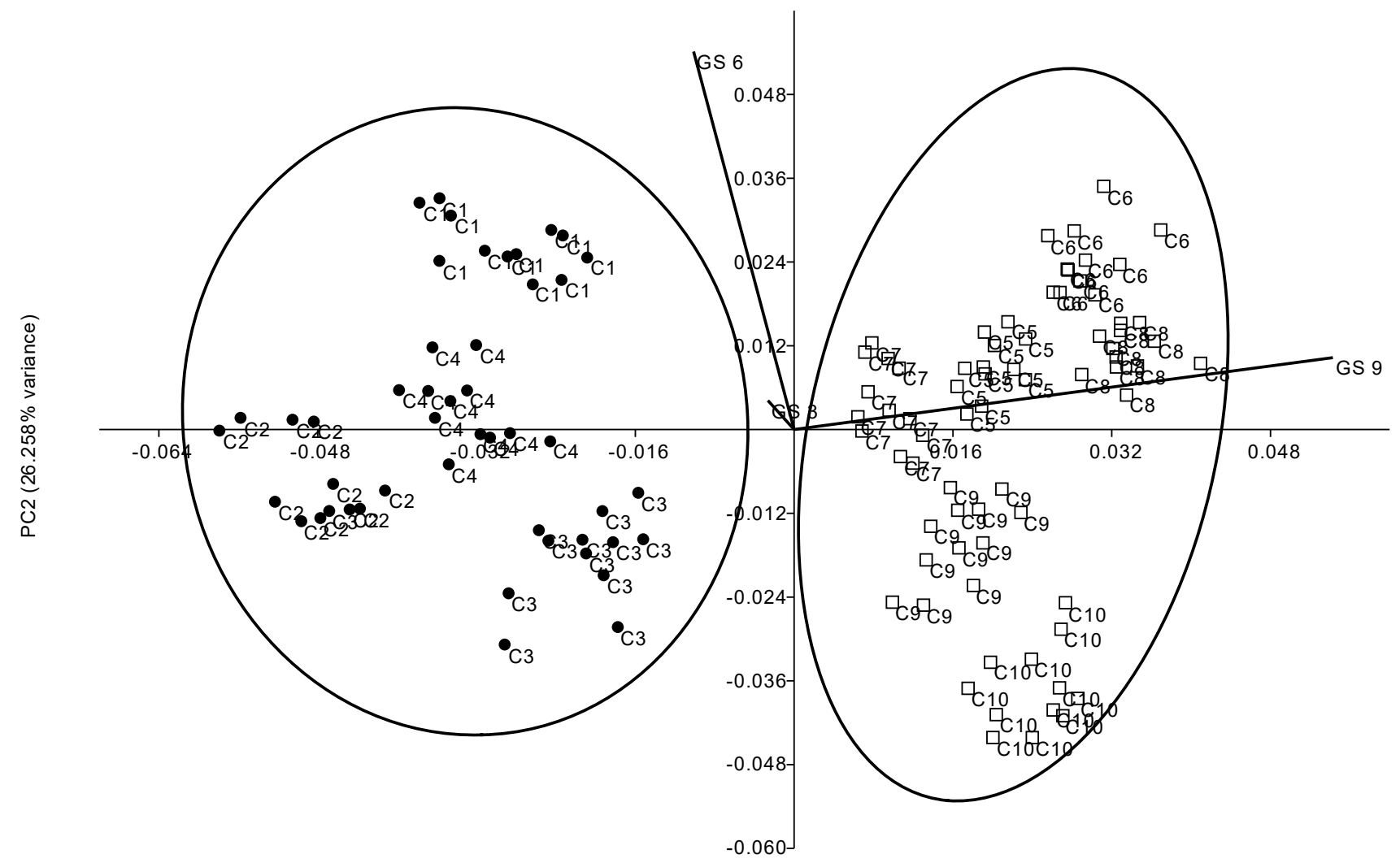

PC1 (57.318\% variance)

Figure 4 Biplot for awned and non-awned morphological character in 10 wheat cultivars based on fractal dimension (D); GS 3, GS 6, GS 9 biplot represented by growth stages. C1 - Avenue, C2 - Pitbull, C3 - GK Koros, C4 - Illico, C5 - GK Rozi, C6 - PG 101, C7 - GK Bekes, C8 - GK 102, C9 - Antonius, C10 - Stefanus

\section{CONCLUSIONS}

Fractal analysis was an appropriate tool with a high capacity to extract data expressed in dynamics by the studied biological material. The studied wheat cultivars showed significant variation of the fractal dimension $(D)$ depending on the vegetation stages and the morphological and anatomic properties.

At the physiological maturity stage, $\mathrm{BBCH}$ code 99 , the morpho-anatomical peculiarities of the studied genotypes (awned/non-awned) have generated a high variance that was illustrated by the fractal dimension, which facilitated the differentiation of the awned cultivars from the non-awned ones based on fractal values.

On the basis of fractal dimensions, PCA analysis has facilitated the differentiation of the two groups of awned/non-awned varieties with a variation of $57.258 \%$ in $P C 1$ and $26.356 \%$ in $P C 2$ and the Cluster analysis method has revealed the existence of various degrees of similarity and morphological and temporal variability in the studied cultivars.

\section{Acknowledgements}

The research is supported by the project "Ensuring excellence in the activity of RDI within USAMVBT" code 35PFE, submitted in the competition Program 1 Development of the national system of research development, Subprogram 1.2 - Institutional performance, Institutional development projects - Development projects of excellence in RDI.

The authors would like to thank the management of the Didactic and Experimental Station of BUASVM Timisoara and its partners for facilitating the setting up of the experiment and research activity.

\section{REFERENCES}

[1] Backes, A. R., Casanova, D., \& Bruno, O. M. (2012). Color texture analysis based on fractal descriptors. Pattern Recognition Letters, 45(5), 1984-1992. https://doi.org/10.1016/j.patcog.2011.11.009

[2] Herbei, M. V. \& Sala, F. (2015). Use landsat image to evaluate vegetation stage in sunflower crops. AgroLife Scientific Journal, 4(1), 79-86. 
[3] Herbei, M. \& Sala, F. (2016). Biomass prediction model in maize based on satellite images. AIP Conference Proceedings, 1738, 350009-1 - 350009-4. https://doi.org/10.1063/1.4952132

[4] Herbei, M., Sala, F., \& Boldea, M. (2015a). Relation of Normalized Difference Vegetation Index with Some Spectral Bands of Satellite Images. AIP Conference Proceedings, 1648, 670003-1 - 670003-4. https://doi.org/10.1063/1.4912898

[5] Herbei, M., Sala, F., \& Boldea, M. (2015b). Using mathematical algorithms for classification of LANDSAT 8 Satellite Images. AIP Conference Proceedings, 1648, 670004-1 - 670004-4. https://doi.org/10.1063/1.4912899

[6] Kilic, K. I. \& Abiyev, R.H. (2011) Exploiting the synergy between fractal dimension and lacunarity for improved texture recognition. Signal Processing, 91(10), 2332-2344. https://doi.org/10.1016/j.sigpro.2011.04.018

[7] Markovic, I., Markovic, D., Ilic, J., Simonovic, V., Veg, E., Šiniković, G., \& Gubeljak, N. (2018). Application of statistical indicators for digital image analysis and segmentation in sorting of agriculture products. Tehnički Vjesnik, 25(6), 1739-1745. https://doi.org/10.17559/tv-20171129091703

[8] Rawashdeh, H. \& Sala, F. (2016). The effect of iron and boron foliar fertilization on yield and yield components of wheat. Romanian Agricultural Research, 33, 1-9.

[9] Sala, F., Rujescu, C., \& Constantinescu, C. (2016). Causes and solutions for the remediation of the poor allocation of $\mathrm{P}$ and $\mathrm{K}$ to wheat crops in Romania. AgroLife Scientific Journal, 5(1), 184-193. https://doi.org/10.5336/healthsci.2016-51534

[10] Volchuk, V., Klymenko, I, Kroviakov, S., \& Orešković, M. (2018). Method of material quality estimation with usage of multifractal formalism. Tehnički Glasnik, 12(2), 93-97. https://doi.org/10.31803/tg-20180302115027

[11] Mandelbrot, B. B. (1983). The Fractal Geometry of Nature, Revised and Enlarged Edition, W.H. Freeman and Co., New York.

[12] Backes, A. R. \& Bruno, O. M. (2010). Shape classification using complex network and multi-scale fractal dimension. Pattern Recognition Letters,31(1), 44-51. https://doi.org/10.1016/j.patrec.2009.08.007

[13] Xu, Y, Huang, S, Ji, H., \& Fernmüller, C. (2012). Scalespace texture description on SIFT-like textons. Computer Vision and Image Understanding, 116(9), 999-1013. https://doi.org/10.1016/j.cviu.2012.05.003

[14] Zhao, Y., Jia, W., Hu, R. X., \& Min, H. (2013). Completed robust local binary pattern for texture classification. Neurocomputing, 106, 68-76. https://doi.org/10.1016/j.neucom.2012.10.017

[15] Bianconi, F., Gonzáles, E., Fernández, A., \& Saetta, S. A. (2012). Automatic classification of granite tiles through colour and texture features. Expert Systems with Applications, 39(12), 11212-11218. https://doi.org/10.1016/j.eswa.2012.03.052

[16] Florindo, J. B., Sikora, M. S., Pereira, E. C., \& Bruno, O. M. (2013). Characterization of nanostructured material images using fractal descriptors. Physica A: Statistical Mechanics and its Applications, 392(7), 1694-1701. https://doi.org/10.1016/j.physa.2012.11.020

[17] Plotze, R. O., Falvo, M., Pádua, J. G., Bernacci, L. C., Vieira, M. L. C., Oliveira, G. C. X., \& Bruno, O. M. (2005). Leaf shape analysis using the multiscale Minkowski fractal dimension, a new morphometric method: A study with Passiflora (Passifloraceae). Canadian Journal of Botany, 83(3), 287-301. https://doi.org/10.1139/b05-002

[18] Cope, J. S., Corney, D., Clark, J. Y., Remagnino, P., \& Wilkin, P. (2012). Plant species identification using digital morphometrics: A review. Expert Systems with Applications, 39(8), 7562-7573. https://doi.org/10.1016/j.eswa.2012.01.073

[19] Sala, F. \& Rujescu, C. (2017). Fractal analysis to evaluate the productivity elements at wheat spike. Annales of West University of Timisoara. Series of Biology, 20(1), 91.

[20] Alados, C. L., Pueyo, Y., Navas, D., Cabezudo, B., Gonzales, A., \& Freeman, D. C. (2005). Fractal analysis of plant spatial patterns: a monitoring tool for vegetation transition shifts. Biodiversity and Conservation, 14(6), 14531468. https://doi.org/10.1007/s10531-004-9669-3

[21] Linares, J. C., Esteban, F. J., Viñegla, B., \& Carreira, J. A. (2006). A computational analysis of multi-temporal vegetation changes using the fractal dimension spectrum. HarFA e-journal, 97-100.

[22] Li, T., He, B., Zhang, Y., Tian, J., He, X., Yao, Y., \& Chen, X. (2016). Fractal analysis of soil physical and chemical properties in five tree-cropping systems in southwestern China. Agroforestry systems, 90(3), 457-468. https://doi.org/10.1007/s10457-015-9868-9

[23] Buchníček, M., Nežádal, M., \& Zmeškal, O. (2000). Numeric Calculation of Fractal Dimension. Proceedings: $3^{\text {rd }}$ Prediction Conference, Faculty of Technology Zlin, BUT Brno, October 2-3, 10-15.

[24] Nežádal, M., Zmeškal, O., \& Buchníček, M. (2001). The BoxCounting: Critical Study. Proceedings: $4^{\text {th }}$ Prediction Conference, Institute of Information Technologies, Faculty of Technology, Tomas Bata University in Zlin, October 25$26,18$.

[25] Roy, A., Perfect, E., Dunne, W. M., \& McKay, L. D. (2007). Fractal characterization of fracture networks: An improved box-counting technique. Journal of Geophysical Research: Solid Earth, 112(B12). https://doi.org/10.1029/2006jb004582

[26] Rasband, W. S. (2012). ImageJ: Image processing and analysis in Java. Astrophysics Source Code Library.

[27] Karperien, A. (2013). FracLac for ImageJ. Charles Sturt University.

[28] Hammer, Ø., Harper, D. A. T., \& Ryan, P. D. (2001). PAST: Paleontological statistics software package for education and data analysis. Palaeontologia Electronica 4(1), 1-9.

[29] Sala, F., Iordănescu, O., \& Dobrei, A. (2017). Fractal analysis as a tool for pomology studies: Case study in apple. AgroLife Scientific Journal, 7(2), 224-233.

[30] Du, J. X., Wang, X. F., \& Zhang, G. J. (2007). Leaf shape based plant species recognition. Applied Mathematics and Computation, 185, 883-893. https://doi.org/10.1016/j.amc.2006.07.072

[31] Araujo Mariath, J. E., Santos, R. P., \& Santos, R. P. (2010). Fractal dimension of the leaf vascular system of three Relbunium species (Rubiaceae). Revista Brasileira de Biociencias, 8(1), 30-33.

Retrieved from http://www.ufrgs.br/seerbio/ojs/index.php $/ \mathrm{rbb} /$ article/view/1247

[32] Yiyu, C., Minjun, C., \& Welsh, W. J. (2003). Fractal fingerprinting of chromatographic profiles based on wavelet analysis and its application to characterize the quality grade of medicinal herbs. Journal of Chemical Information and Computer Sciences, 43(6), 1959-1965. https://doi.org/10.1021/ci034090d

[33] Istepanian, R. S., Sungoor, A., \& Nebel, J. C. (2008). Fractal dimension and wavelet decomposition for robust microarray data clustering. Proceedings: $200830^{\text {th }}$ Annual international Conference of the IEEE Engineering in Medicine and Biology Society, 4106-4109. https://doi.org/10.1109/iembs.2008.4650112

[34] Olgun, M., Onarcan, A. O., Özkan, K., Ișik, Ş., Sezer, O., Özgişi, K., Ayter, N. G., Başçiftçi, Z. B., Ardiç, M., \& Koyuncu, O. (2016). Wheat grain classification by using dense SIFT features with SVM classifier. Computers and Electronics in Agriculture, 122, 185-190. https://doi.org/10.1016/j.compag.2016.01.033 
[35] Zayas, I. Y., Martin, C. R., Steele, J. L., \& Katsevich, A. (1996). Wheat classification using image analysis and crushforce parameters. Transactions of the ASAE, 39(6), 21992204. https://doi.org/10.13031/2013.27725

\section{Contact information:}

Ciprian RUJESCU, Asist. Professor

Banat University of Agricultural Sciences and Veterinary Medicine "King Michael I of Romania", from Timisoara, Mathematic and Statistics,

Calea Aradului, 119, 300645, Timisoara, Romania

E-mail: rujescu@usab-tm.ro

Cosmin POPESCU, Professor

Banat University of Agricultural Sciences and Veterinary Medicine "King Michael

I of Romania", from Timisoara, Remote sensing and GIS

Calea Aradului, 119, 300645, Timisoara, Romania

E-mail: cosmin_popescu@usab-tm.ro

\section{Hamzeh RAWASHDEH, PhD}

Water Management and Environment Research Department,

National Center for Agricultural Research and Extension,

P.O. Box 639, Baqa 19381, Jordan

E-mail: hamz_rawashdeh@yahoo.com

\section{Florin SALA, Professo}

(Corresponding author)

Banat University of Agricultural Sciences and Veterinary Medicine "King Michael

I of Romania", from Timisoara, Soil Science and Plant Nutrition,

Calea Aradului, 119, 300645, Timisoara, Romania

E-mail: florin_sala@usab-tm.ro 